NBER WORKING PAPER SERIES

\title{
ON THE DESIRABILITY OF A REGIONAL BASKET CURRENCY ARRANGEMENT
}

\author{
Eiji Ogawa \\ Takatoshi Ito \\ Working Paper 8002 \\ http://www.nber.org/papers/w8002 \\ NATIONAL BUREAU OF ECONOMIC RESEARCH \\ 1050 Massachusetts Avenue \\ Cambridge, MA 02138 \\ November 2000
}

This paper was presented at the CEPII-KIEP-ADBI conference, December 17-18, 1999. The authors are grateful to Gang Yi, Kenichi Ohno, and other participants of the reference, and to anonymous referee, for useful and constructive comments. Views expressed here are authors' own, and not necessarily those of institutions with which the authors were affiliated at present or in the past.

(C) 2000 by Eiji Ogawa and Takatoshi Ito. All rights reserved. Short sections of text, not to exceed two paragraphs, may be quoted without explicit permission provided that full credit, including $(\mathrm{c}$ notice, is given to the source. 
On the Desirability of a Regional Basket Currency Arrangement

Eiji Ogawa and Takatoshi Ito

NBER Working Paper No. 8002

November 2000

JEL No. F31, F33, O11

\begin{abstract}
This paper considers a theoretical model to examine an optimal exchange rate regime for (Asian) emerging market economies that export goods to the U.S., Japan, and neighboring countries. The optimality of the exchange rate regime is defined as minimizing the fluctuation of trade balances, in the environment where the yen-dollar exchange rate fluctuates. Since the de facto dollar peg regime is blamed as one of the factors that caused the Asian currency crisis, the question of the optimal exchange rate regime is quite relevant in Asia. The novelty of this paper is to show how an emerging market economy's choice of the exchange rate regime (or weights in the basket) is dependent on the neighboring country's. The dollar weights in the currency baskets of the two countries are determined as a Nash equilibrium. In general, there are multiple equilibria, and a "coordination failure" may result.
\end{abstract}

Eiji Ogawa

Department of Commerce

Hitotsubashi University

Kunitachi, Tokyo 186-8601

Japan

cc00104@srv.cc.hit-u.ac.jp
Takatoshi Ito

Deputy Vice Minister of International Affairs

Ministry of Finance

3-1-1, Kasumigaseki, Chiyoda

Tokyo 100 Japan

and NBER

takatoshi.ito@mof.go.jp 


\section{Introduction}

One of the lessons from the Asian Currency Crises is the danger of the de facto dollar peg adopted by the Asian economies that had extensive trade and investment relationship with countries other than the United States. ${ }^{1}$ When the yen appreciated vis-à-vis the US dollar, the Asian economies enjoyed the boom, or a bubble in some cases, due to increased exports. But, when the yen depreciated, the Asian economies tended to experience a recession, or a burst bubble. The experience of the Asian boom and bust in the 1990s, along with the yen-dollar exchange rate fluctuation, is a stark reminder of risk of the fixed exchange rate regime. An obvious solution for this problem is to increase flexibility of the exchange rate. If the baht had appreciated during the yen appreciation phase of the 1993-95, the extent of overheating in Thailand might have been limited; and if the baht had depreciated along with the yen in 1996-97, then the decline in exports could have been mitigated. This kind of exchange rate flexibility can be achieved by a flexible exchange rate regime which keeps the real effective exchange rate relatively stable.

An obvious insight here is that an emerging market economy, which exports 
to the United States and Japan, is well advised to consider managed exchange rate regimes, in order to avoid excessive volatility of the real effective exchange rate. ${ }^{2}$ The questions to be considered include how to determine a reference rate as an appropriate real effective exchange rate and how much fluctuation is excessive.

The optimality of the exchange rate regime is defined as the one that minimizes the fluctuation of the trade balances, when the yen-dollar exchange rate fluctuates. Ito, Ogawa, and Sasaki (1998) proposed how to calculate the optimal weights when the emerging market economy exports to Japan and the United States only. The optimal weights were calibrated with some assumptions on the demand elasticities and export shares. In this paper, we extend the Ito, Ogawa, and Sasaki model to include a neighboring emerging market as well as Japan and the United States. A typical Asian economy exports about one-third to the United States and one-third to Japan, and the rest to countries in the Asian region (and EU). Therefore, to simplify, we consider the case that country A (B, respectively) exports to the U.S., Japan, and country B (A, respectively). Therefore, the real effective exchange rate calculation includes the currency of neighboring country. What makes difficult and interesting in this model is 
that the optimal weights may depend on what the neighboring country is adopting as weights. In the extreme case, if country A is adopting the dollar peg, country B should adopt the dollar peg; and if country B is adopting the dollar peg, then country A should adopt the dollar peg. Namely, the dollar peg is a Nash equilibrium. However, if country $\mathrm{A}$ is using a currency basket which mirrors the export shares, adjusted for demand elasticities, then country B should adopt a (similar) currency basket; and if country B is using a currency basket, then country A should adopt a currency basket. This trade-weighted currency basket is also a Nash equilibrium.

Although the paper is motivated by the recent Asian experiences, the application is not limited to Asia. Results obtained in this paper are relevant to any developing countries with a trading structure with export destinations including different currency areas.

Which of the Nash equilibria is chosen depends on the inertia as well as rational calculation. If countries can coordinate, then they should choose the best among Nash equilibria. This process of choosing the optimal Nash equilibrium can be regarded as a regional currency arrangement. Coordination failure could occur if a country has some obstacles for coordination from 
political or social obstacles against breaking inertia. What this paper shows is that coordinate managed float by the two countries would increase the stability in the trade balance fluctuations.

The rest of the paper is organized as follows. Section 2 explains the model. We assume that the Marshall-Lerner condition, which means that depreciation of the local currency will increase the net trade surpluses, is satisfied throughout the paper. Section 3 examines what the Marshall-Lerner condition implies in our oligopoly model with imported parts and It also examines in what situation the Marshall-Lerner condition is satisfied in the model. Section 4 defines and solves for an optimal currency regime. We introduce the exchange rate policy of the monetary authorities of the two countries in order to analyze interdependence and coordination failure between their exchange rate policies.

\section{Model}

(1) Settings

Our earlier work, Ito, Ogawa, and Sasaki (1998), considered the question of choosing optimal weights in the basket currency system for a country that exports goods to the United States and Japan. An Asian country was modeled 
as a one-sector economy where a representative firm assembles parts imported from Japan and the United States into manufactured products. ${ }^{3}$ The representative firm in one Asian country was assumed to compete with Japanese firms and/or U.S. firms in the Japanese and U.S. markets. We extend our earlier model to include another neighbor country in the model in order to analyze interactions of the exchange rate policies among Asian countries. We assume that a representative firm in country A imports parts from the United States and Japan and exports its products to markets in the United States, Japan, and country B as well as a domestic market. ${ }^{4}$ Also, a representative firm in country B imports parts from the United States and Japan and supplies its products to markets in the United States, Japan, and country A as well as a domestic market. We assume that prices of parts from the United States and Japan are given in terms of their production country's currency.

Asian countries export their goods and services mainly to Japan, the United States, and neighboring Asian countries. For example, Thailand exports one-fourth to Japan, one-fifth to NIES (Korea, Singapore, Hong Kong, and Taiwan) and ASEAN-4 countries (Thailand, Philippines, Indonesia, and Malaysia), one-seventh to the United States. These three categories account for more than 
60 percent. Similarly, Malaysia exports to 22 percent, 34 percent and 17 percent to Japan, to the United States, and to Asian countries, respectively. The sum of these three categories reaches 72 percent. The structure is similar in Indonesia and the Philippines. Table 1 shows the export shares by destination to Japan, the United States, Asian countries, and four European countries (Germany, France, UK, and Italy). Therefore, the assumptions of the model, Country A exports to Japan, the United States, and neighboring country B, are realistic.

Each market in countries $A$ and $B$ is supposed to be a duopoly market where both country A and B firms compete with each other. Markets in the United States and Japan are under monopolistic competition. Country A and B firms compete with many domestic firms in each of the U.S. and Japanese markets. They supplies their products in the U.S. and Japanese monopolistically competitive markets given average prices of their domestic products made in the United States and Japan. We assume that prices of the products made in the U.S. and Japan are kept unchanged (exogenous to this model) for simplicity. Moreover, we assume that all firms in countries A and B have identical cost functions. Each firm maximizes its profits in terms of its own home currency. 
Profits of each firm in countries A and B in terms of its own home currency $\mathrm{A}$ and $\mathrm{B}\left(\pi_{i}(i=A, B)\right)$ is calculated as

$$
\begin{array}{r}
\pi_{i}=P_{i}^{i} d_{i}\left(q_{i}\right)+E^{i / Y} P_{J}^{i} f_{i}\left(q_{J}^{i}\right)+E^{i / \$} P_{U S}^{i} g_{i}\left(q_{U S}^{i}\right)+E^{i / j} P_{j}^{i} h_{i}\left(q_{j}\right) \\
-\left(E^{i / Y} P_{m}^{Y} \omega_{m}^{J}-E^{i / \$} P_{m}^{\$} \omega_{m}^{U S}\right) Q_{i}-C\left(Q_{i}\right)
\end{array}
$$

for $i=A, B$ and $j=B, A$, where $P_{i}^{i}$ denotes price of the country $i$ firm's products in domestic market in terms of home currency $(i=A, B) ; \quad P_{j}^{i}$ price of the country $i$ firm's products in country $j$ market in terms of country $j$ currency $(i=A, B$, and $j=J$ (Japan); US (the United States), $B, A) ; P_{m}^{i}$ price of parts imported from country $i$ in terms of country $i$ currency $(i=J, \quad U S) ; \quad Q_{i}$ $\left(Q_{i}=d_{i}\left(q_{i}\right)+f_{i}\left(q_{J}^{i}\right)+g_{i}\left(q_{U S}^{i}\right)+h_{i}\left(q_{j}\right)\right)$ outputs of the country A firms products $(i=$ $A, B$ and $j=B, A) ; d_{i}$ demand function for the country $i$ firm's products in the domestic market; $f_{i}$ demand function for the country $i$ firm's products in the Japanese market; $g_{i}$ demand function for the country $i$ firm's products in the U.S. market; $h_{i}$ demand function for the country $i$ firm's products in the neighbor country's market; $C()$ cost function $\left(C^{\prime}<0\right.$, we assume that $C^{\prime \prime}=0$ for simplicity); $q_{i}^{j} \equiv P_{i}^{j} / P_{i}$ relative price of the country $j$ firm's products relative to country $i$ in country $i$ market $(i=J, U S$ and $j=B, A) ; \quad q_{i}$ relative price of the country $i$ firm's products relative to the neighbor country's product in the 
country $i$ market; $P_{i}$ price of the country $i$ products in country $i$ market in terms of country $i$ currency $(i=J, U S) ; E^{j / i}$ exchange rate of currency $i$ in terms of country $j$ currency $(i=\$, B$ and $j=A, B)$; and $\omega_{m}^{i}$ share of parts imported from country $i \quad(i=J, U S), \omega_{m}^{J}+\omega_{m}^{U S}=1$.

From first order conditions of equation (2.1), profit-maximizing prices of the country $i$ firm in Japanese, the United States, country A and B markets, respectively, are derived as

$$
\begin{gathered}
P_{J}^{i}=\mu_{J}^{i} \frac{C_{i}}{E^{i / Y}} \\
P_{U S}^{i}=\mu_{U S}^{i} \frac{C_{i}}{E^{i / \$}} \\
P_{i}^{i}=\mu_{i}^{i} C_{i} \\
P_{j}^{i}=\mu_{j}^{i} \frac{C_{i}}{E^{i / j}} \\
C_{i} \equiv \omega_{m}^{J} E^{i / Y} P_{m}^{J}+\omega_{m}^{U S} E^{i / \$} P_{m}^{U S}+C^{\prime}\left(Q_{i}\right)
\end{gathered}
$$

for $i=A, B$ and $j=B, A$, where $\mu_{i}^{j} \equiv \varepsilon_{i}^{j}\left(q_{i}^{j}\right) /\left\{\varepsilon_{i}^{j}\left(q_{i}^{j}\right)-1\right\}$ denotes markups of the country A firm's products in country $i$ market $(i=J, U S, A, B$ and $j=A, B), \varepsilon_{i}^{j}$ denotes price elasticity of demand for the country $j$ firm's product in country $i$ market $(i=$ $J, U S, A, B$ and $j=A, B$ ). We assume that $\varepsilon_{i}^{j}>1$.

We convert equations (2.2) to (2.5) into a logarithm form and derive reaction functions of country $A$ firm in Japanese, the U.S., and country $A$ and $B$ markets 
given the prices of the products made in Japan, the United States, and country

$B$, respectively.

$$
\begin{gathered}
\log P_{J}^{i}=\frac{\eta_{J}^{i}}{1+\eta_{J}^{i}} \log P_{J}+\frac{1}{1+\eta_{J}^{i}}\left(\log C_{i}-\log E^{i / Y}\right) \\
\log P_{U S}^{i}=\frac{\eta_{U S}^{i}}{1+\eta_{U S}^{i}} \log P_{U S}+\frac{1}{1+\eta_{U S}^{i}}\left(\log C_{i}-\log E^{i / \$}\right) \\
\log P_{i}^{i}=\frac{\eta_{i}^{i}}{1+\eta_{i}^{i}} \log P_{i}^{j}+\frac{1}{1+\eta_{i}^{i}} \log C_{i} \\
\log P_{j}^{i}=\frac{\eta_{j}^{i}}{1+\eta_{j}^{i}} \log P_{j}^{j}+\frac{1}{1+\eta_{j}^{i}}\left(\log C_{i}-\log E^{i / j}\right)
\end{gathered}
$$

for $i=A, B$ and $j=B, A$, where $\eta_{i}^{j} \equiv \mu_{i}^{j^{j}} q_{i}^{j} / \mu_{i}^{j}$ denotes price elasticity of the markups of the country $j$ firm's products in country $i$ market for $i=J, U S, A, B$ and $j=A, B$.

For simplicity, we assume that price elasticities of demand for the country $A$ and B firms' product are equal to each other in each of the country $A$ and $B$ markets. That is, $\varepsilon_{A}^{B}=\varepsilon_{A}^{A}=\varepsilon_{A}$ and $\varepsilon_{B}^{A}=\varepsilon_{B}^{B}=\varepsilon_{B}$. Thus, price elasiticities of the markups of country $A$ and $B$ firms' products are equal to each other in each of the country $A$ and $B$ markets. That is, $\eta_{A}^{B}=\eta_{A}^{A}=\eta_{A}$ and $\eta_{B}^{A}=\eta_{B}^{B}=\eta_{B}$.

From equation (2.9), we obtain equilibrium prices for the country $A$ and $B$ firms' products in the duopoly market of countries $A$ and $B$, respectively:

$$
\begin{aligned}
\log P_{i}^{i} & =\frac{1+\eta_{i}}{1+2 \eta_{i}} \log C_{i}+\frac{\eta_{i}}{1+2 \eta_{i}}\left(\log C_{j}+\log E^{i / j}\right) \\
\log P_{i}^{j} & =\frac{\eta_{i}}{1+2 \eta_{i}} \log C_{i}+\frac{1+\eta_{i}}{1+2 \eta_{i}}\left(\log C_{j}+\log E^{i / j}\right)
\end{aligned}
$$


for $i=A, B$ and $j=A, B$.

Equations (2.11) and (2.12) shows that the equilibrium prices of country $A$ and $B$ firms' products depend on not only marginal total costs of country $A$ and $B$ products but also the exchange rate of currency $A$ vis-à-vis currency $B$.

(2) Relative prices and demand functions

From equations (2.7) and (2.8), we obtain equilibrium relative prices of country $A$ and $B$ firms' products relative to the Japanese and the U.S. domestic products in the Japanese and U.S. markets, respectively.

$$
\begin{gathered}
\log q_{J}^{i}=\varphi_{J}^{i}\left(\log C_{i}-\log E^{i / Y}-\log P_{J}\right) \\
\log q_{U S}^{i}=\varphi_{U S}^{i}\left(\log C_{i}-\log E^{i / \$}-\log P_{U S}\right)
\end{gathered}
$$

where $\varphi_{j}^{i} \equiv \frac{1}{1+\eta_{j}^{i}}$ for $i=A, B$ and $j=J$, US .

Moreover, from equations (2.11) and (2.12), we obtain equilibrium relative prices of country $A$ products relative to country $B$ products in each of the country $A$ and $B$ markets, respectively.

$$
\log q_{i}=\varphi_{i}\left(\log C_{i}-\log C_{j}+\log E^{i / j}\right)
$$

where $\varphi_{i} \equiv \frac{1}{1+2 \eta_{i}}$ for $i=A, B$

Equation (2.15) shows that the equilibrium relative prices depend on the 
marginal total costs and the exchange rate of currency $A$ vis-à-vis currency

$B$.

We specify demand functions for country $A$ and $B$ firms' products exporting

to the Japanese, the U.S., countries $A$ and $B$ markets from equations (2.13) to

$(2.15):$

$$
\begin{gathered}
\log d_{i}=\varepsilon_{i} \varphi_{i}\left(\log C_{j}-\log C_{i}+\log E^{i / j}\right) \\
\log f_{i}=\varepsilon_{J}^{i} \varphi_{J}^{i}\left(\log P_{J}+\log E^{i / Y}-\log C_{i}\right) \\
\log g_{i}=\varepsilon_{U S}^{i} \varphi_{U S}^{i}\left(\log P_{U S}+\log E^{i / \$}-\log C_{i}\right) \\
\log h_{i}=\varepsilon_{i} \varphi_{i}\left(\log C_{j}-\log C_{i}+\log E^{i / j}\right)
\end{gathered}
$$

for $i=A, B$ and $j=B, A$. The equations show that the demands depend on some exchange rates as well as the marginal total costs, the Japanese and U.S. prices.

\section{Effects of exchange rates on trade balances}

In the next section, we introduce the exchange rate policy of the monetary authorities of the two countries into our model under the Marshall-Lerner condition to analyze interdependence and coordination failure between their exchange rate policies. In this section, we examine what the Marshall-Lerner condition implies in the model where domestic firms import parts from Japan 
and the United States and in what situation the Marshall-Lerner condition is satisfied in the model.

At first, we analyze effects of changes in the exchange rates on trade balances of countries $A$ and $B$. In the model, trade balances are equal to a total exports (to Japan and US) less the sum of total costs of imported parts (from Japan and US) and imports from the neighbor country. Therefore, the trade balances denominated in the dollar for countries A and B, respectively, are shown as:

$$
T_{i}=E^{i / Y} P_{J}^{i} f_{i}+E^{i / \$} P_{U S}^{i} g_{i}+E^{i / \$} E^{\$ / j} P_{j}^{i} h_{i}-E^{i / Y} P_{m}^{J} \omega_{m}^{J} Q_{i}-E^{i / \$} P_{m}^{U S} \omega_{m}^{U S} Q_{i}-P_{i}^{j} h_{j}
$$

for $i=A, B$ and $j=B, A$.

We derive a relationship between changes in the trade balances and those in the exchange rates from equations (3.1).

$$
\begin{aligned}
\hat{T}_{i} & =\left\{\left(\tau_{i}^{E x J}-\tau_{i}^{I m J}\right) \hat{E}^{i / Y}+\left(\tau_{i}^{E x U S}-\tau_{i}^{I m J}-\tau_{i}^{I m U S}\right) \hat{E}^{i / \$}-\tau_{i}^{E x j} \hat{E}^{j / \$}\right\} \\
& +\left\{\tau_{i}^{E x J} \hat{P}_{J}^{i}+\tau_{i}^{E x U S} \hat{P}_{U S}^{i}+\tau_{i}^{E x j} \hat{P}_{j}^{i}-\tau_{i}^{I m j} \hat{P}_{i}^{j}\right\} \\
& +\left\{\tau_{i}^{E x J} \hat{f}_{i}+\tau_{i}^{E x U S} \hat{g}_{i}+\tau_{i}^{E x j} \hat{h}_{i}-\tau_{i}^{I m J U S} \hat{Q}_{i}-\tau_{i}^{I m j} \hat{h}_{j}\right\}
\end{aligned}
$$

where $\tau_{i}^{E x J} \equiv E^{i / Y} P_{J}^{i} f_{i} / T_{i}, \tau_{i}^{E x U S} \equiv E^{i / \$} P_{U S}^{i} g_{i} / T_{i}, \tau_{i}^{E x j} \equiv E^{i / \$} E^{\$ / j} P_{j}^{i} h_{i} / T_{i}, \quad \tau_{i}^{I m J} \equiv E^{i / Y} P_{m}^{J} \omega_{m}^{J} Q_{i} / T_{i}$, $\tau_{i}^{I m U S} \equiv E^{i / \$} P_{m}^{U S} \omega_{m}^{U S} Q_{i} / T_{i}, \quad \tau_{i}^{I m j} \equiv P_{i}^{j} h_{j} / T_{i}, \quad \tau_{i}^{I m J U S} \equiv\left(E^{i / Y} P_{m}^{J} \omega_{m}^{J}+E^{i / \$} P_{m}^{U S} \omega_{m}^{U S}\right) Q_{i} / T_{i} \quad$ for $i=A, B$ 
and $j=A, B, \hat{x}$ represents a rate of changes in variable $x$. It is assumed, as mentioned earlier, that prices of the products made in Japan and the United States are kept unchanged.

The first line of equation (3.2) represents a direct price effect of exchange rates on trade balances. The second line of (3.2) represents an indirect effect of exchange rates via PTM (pricing to market) behaviors of country $A$ and $B$ firms. The third line of (3.2) represents an indirect effect of exchange rates on trade balances via trade volumes. It is necessary for the Marshall-Lerner condition that the volume effect (third line of equation (3.2)) dominates the sum of direct price effect (first line of equation (3.2)) and PTM effect (second line of equation (3.2)). We consider whether the Marshall-Lerner condition is always satisfied in our model if the volume effect dominates the sum of direct price effect and PTM effect. For the simplicity sake, we examine whether depreciation of the local currency have positive effect on the net trade volumes, that is, export volumes minus import volumes.

The indirect effect via trade volume (third line of (3.2)) can be described as a function of the changes in the exchange rates as follows:

$$
\tau_{i}^{E x J} \hat{f}_{i}+\tau_{i}^{E x U S} \hat{g}_{i}+\tau_{i}^{E x j} \hat{h}_{i}-\tau_{i}^{I m J U S} \hat{Q}_{i}-\tau_{i}^{I m j} \hat{h}_{j}=A^{i / Y} \hat{E}^{i / Y}+A^{i / \$} \hat{E}^{i / \$}+A^{j / Y} \hat{E}^{j / Y}+A^{j / \$} \hat{E}^{j / \$} \text { (3.3) }
$$


where $A^{i / Y}=\tau_{i}^{T J} \varepsilon_{J}^{i} \varphi_{J}^{i}\left(1-\alpha_{i 1}\right)-\tau_{i}^{T U S} \varepsilon_{U S}^{i} \varphi_{U S}^{i} \alpha_{i 1}+\left(\tau_{i}^{T B} \varepsilon_{i} \varphi_{j}+\tau_{i}^{I m j} \varepsilon_{i} \varphi_{i}\right) \alpha_{i 1}$

$$
\begin{gathered}
A^{i / \$}=\tau_{i}^{T U S} \varepsilon_{U S}^{i} \varphi_{U S}^{i}\left(1-\alpha_{i 2}\right)-\tau_{i}^{T J} \varepsilon_{J}^{i} \varphi_{J}^{i} \alpha_{i 2}+\left(\tau_{i}^{T B} \varepsilon_{j} \varphi_{j}+\tau_{i}^{I m j} \varepsilon_{i} \varphi_{i}\right)\left(1+\alpha_{i 2}\right), \\
A^{j / Y}=-\left\{\tau_{i}^{T B} \varepsilon_{j} \varphi_{j}+\tau_{i}^{I m j} \varepsilon_{i} \varphi_{i}\right\} \alpha_{j 1}, \\
A^{j / \$}=-\left\{\tau_{i}^{T B} \varepsilon_{j} \varphi_{j}+\tau_{i}^{I m j} \varepsilon_{i} \varphi_{i}\right\}\left(1+\alpha_{j 2}\right), \\
\tau_{i}^{T J} \equiv \tau_{i}^{E x J}-\tau_{i}^{I m J U S} w_{J}^{i}, \tau_{i}^{T U S} \equiv \tau_{i}^{E x U S}-\tau_{i}^{I m J U S} w_{U S}^{i}, \tau_{i}^{T B} \equiv \tau_{i}^{E x j}-\tau_{i}^{I m J U S} w_{j}^{i} \text { for } i=A, B \text { and } j=B \text {, } A \text { and } \\
0 \leq \alpha_{i 1} \equiv \frac{\omega_{m}^{J} E^{i / Y} P_{m}^{Y}}{C_{i}} \leq 1,0 \leq \alpha_{i 2} \equiv \frac{\omega_{m}^{U S} E^{i / \$} P_{m}^{\$}}{C_{i}} \leq 1 \text { for } i=A, B \text {. Signs of the parameters of } \\
\tau_{i}^{T J}, \tau_{i}^{T U S}, \tau_{i}^{T B} \text {, and } \tau_{i}^{E x j} \text { are positive, if the export industries are putting } \\
\text { value added to the parts imports, converting parts into products for exports. }
\end{gathered}
$$

Hence, we assume that these $\tau$ parameters are positive.

The exchange rates have effects on the product prices, which change the relative prices of the products in the Japanese, the U.S., and country $A$ and $B$ markets. The changes in the relative prices have effects on the demand for the products in these markets. Demand for products made in country $A$ (or $B$ ) is equivalent to export volumes of the country in our model. Since parts are imported from Japan and the United States, and some products are imported from the neighbor country, the exchange rates have effects on imports as well as exports.

In equation (3.3), it is clear that the exchange rates of the neighbor 
country's currency vis-à-vis the yen and the dollar have unambiguous effects on trade volumes. The appreciation of the neighbor currency has positive effects on the trade volume, as the competitiveness of home products would increase. However, the exchange rates of the home currency vis-à-vis the yen and the dollar a priori have ambiguous effect on the trade volumes.

The exchange rate of the home currency vis-à-vis the yen, that is $A^{i / Y}$ is positive-depreciation will cause export volume to increase-if the following inequality is satisfied:

$$
\tau_{i}^{T J} \varepsilon_{J}^{i} \varphi_{J}^{i}\left(1-\alpha_{i 1}\right)+\left(\tau_{i}^{T B} \varepsilon_{i} \varphi_{j}+\tau_{i}^{I m j} \varepsilon_{i} \varphi_{i}\right) \alpha_{i 1}>\tau_{i}^{T U S} \varepsilon_{U S}^{i} \varphi_{U S}^{i} \alpha_{i 1}
$$

Similarly, the exchange rate of the home currency vis-à-vis the dollar, that is $A^{i / \$}$ is positive, if the following inequality is satisfied:

$$
\tau_{i}^{T U S} \varepsilon_{U S}^{i} \varphi_{U S}^{i}\left(1-\alpha_{i 2}\right)+\left(\tau_{i}^{T B} \varepsilon_{j} \varphi_{j}+\tau_{i}^{I m j} \varepsilon_{i} \varphi_{i}\right)\left(1+\alpha_{i 2}\right)>\tau_{i}^{T J} \varepsilon_{J}^{i} \varphi_{J}^{i} \alpha_{i 2}
$$

The right hand side of inequalities (3.4) and (3.5) means that the exchange rates have negative effects on export volumes into the US or Japanese market through increases in cost of imported parts in terms of the home currency. The left hand side means positive effects that depreciation of the home currency increase export volume through relative prices and decrease import volume of parts. 
Thus, the effects of the exchange rates on the trade balances are ambiguous because parts are imported in our model. Depreciation of the home currency against a foreign currency increases price of imported part in terms of the home currency. The increase in domestic price of imported parts decreases optimal outputs and, in turn, decreases export volumes as well as decrease import volume of parts. The depreciation of home currency has an adverse effect on the trade balance if the negative effect on exports via imported part costs is larger than the positive effects that depreciation of the home currency increase export volume through relative prices and decrease import volume of parts. In this case, the Marshall-Lerner condition is not satisfied even if the volume effect (third line of equation (3.2)) dominates the sum of direct price effect (first line of equation (3.2)) and PTM effects (second line of equation (3.2)).

Thus, the dominance of the volume effect is necessary but is not sufficient for the Marshall-Lerner condition to hold in our oligopoly model where domestic firms import parts from Japan and the United States. In addition, it has to be supposed that the direct effect of the exchange rates on export volume is larger than the effect via imported part costs on export volume for the 
Marshall-Lerner condition to hold. Hence, the Marshall-Lerner condition is satisfied in the model when the latter condition as well as the dominance of the volume effect is satisfied.

Next, let us examine the effects of yen's and dollar's appreciation vis-à-vis both home and neighbor's currency on the home trade volume, which is related with stability of exchange rate policy of the two countries analyzed in the next section. These effects are the sum of $A^{i / Y}$ and $A^{j / Y}$ and that of $A^{i / \$}$ and $A^{j / \$}$, respectively. The following equation shows the condition that the yen appreciation (vis-à-vis the both emerging market currencies) produces the positive trade volume effects:

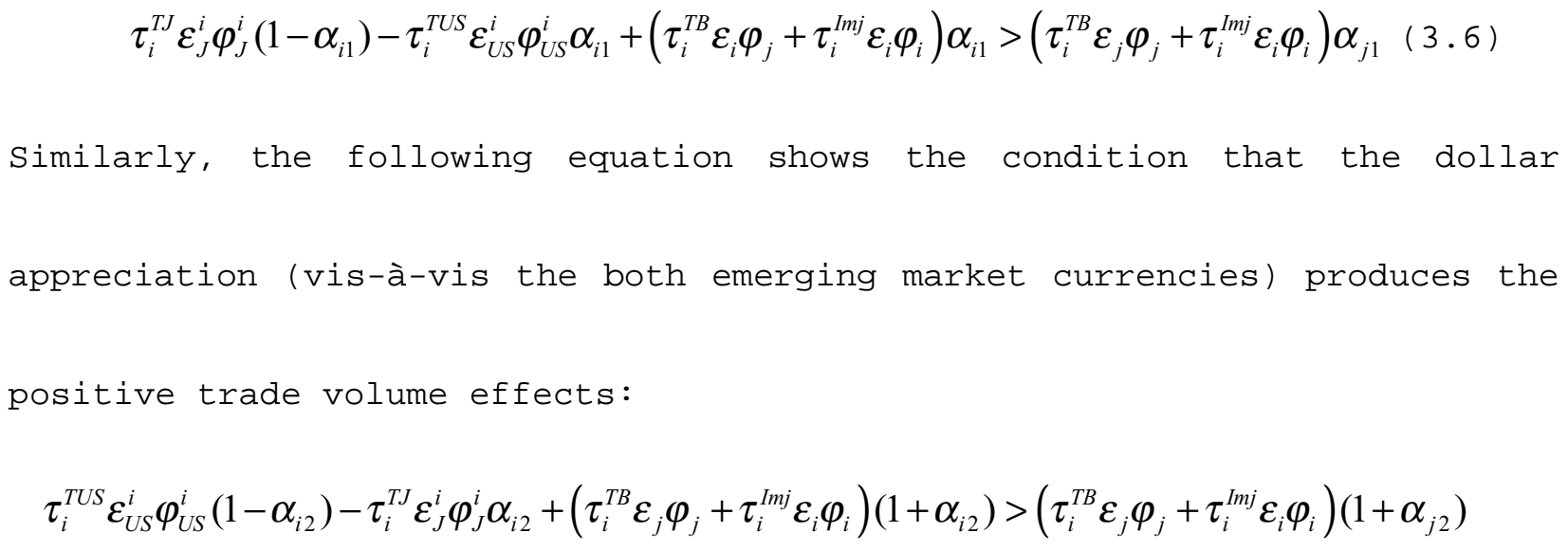$$
\tau_{i}^{T J} \varepsilon_{J}^{i} \varphi_{J}^{i}\left(1-\alpha_{i 1}\right)-\tau_{i}^{T U S} \varepsilon_{U S}^{i} \varphi_{U S}^{i} \alpha_{i 1}+\left(\tau_{i}^{T B} \varepsilon_{i} \varphi_{j}+\tau_{i}^{I m j} \varepsilon_{i} \varphi_{i}\right) \alpha_{i 1}>\left(\tau_{i}^{T B} \varepsilon_{j} \varphi_{j}+\tau_{i}^{I m j} \varepsilon_{i} \varphi_{i}\right) \alpha_{j 1}
$$ 
Then, inequalities (3.4) and (3.5) may be or may not be satisfied. Also, inequalities (3.6) and (3.7) may be or may not be satisfied.

(2) The country $i$ imports parts from Japan only. $\left(\omega_{m}^{U S}=0\right), \alpha_{i 2}=0$

Then, (3.5) is satisfied, but (3.4) may be or may not be satisfied. Moreover, if the production function is symmetric among the neighbor countries - that is, the third term in the left hand side of (3.6) and the right hand side of (3.6) cancel out-then inequality (3.6) is also satisfied.

(3) The country $i$ imports parts from US only. $\left(\omega_{m}^{J}=0\right), \alpha_{i 1}=0$.

Then (3.4) is satisfied, but (3.5) may be or may not be satisfied. Moreover, if the production function is symmetric among the neighbor countries - that is, the third term in the left hand side of (3.7) and the right hand side of (3.7) cancel out-then inequality $(3.7)$ is satisfied.

\section{Exchange rate policies}

In this section, we develop the above two-country model to analyze how exchange rate policy of the monetary authorities in one country can be affected by that in the neighbor country. Interactions of the exchange rate policies conducted emerge in the two country model, because the competitiveness of home 
goods depend on the exchange rate vis-à-vis the neighbor's. At first, we suppose that the monetary authorities of the two countries have the same objective to stabilize fluctuations in trade balances. The policy reaction function of country $i$ is derived in terms of the currency basket in order to stabilize fluctuations in trade balances, given the exchange rate policy of the neighbor country. As a result, it is theoretically possible that a coordination failure may occur. ${ }^{6}$ The coordination failure is a situation where both of the monetary authorities adopt the dollar peg at the same time and a situation where the monetary authorities of one country adopt an optimal currency basket peg while the monetary authorities of the other country adopt the dollar peg.

\section{(1) Optimal currency baskets}

We express the above effects of exchange rates on the trade balances of countries $A$ and $B$ in terms of rates of changes as follows:

$$
\begin{aligned}
& \hat{T}_{A}=A^{A / Y} \hat{E}^{A / Y}+A^{A / \$} \hat{E}^{A / \$}+A^{B / Y} \hat{E}^{B / Y}+A^{B / \$} \hat{E}^{B / \$} \\
& \hat{T}_{B}=B^{B / Y} \hat{E}^{B / Y}+B^{B / \$} \hat{E}^{B / \$}+B^{A / Y} \hat{E}^{A / Y}+B^{A / \$} \hat{E}^{A / \$}
\end{aligned}
$$

Equations (4.1) and (4.2) corresponds to equation (3.2) for country $A$ and $B$. However, by the assumption of the Marshall-Lerner condition, effects of 
equation (3.3) dominate in equation (3.2). Therefore, for the qualitative analysis, we may regard signs of $A$ and $B$ coefficients in equations (4.1) and (4.2) as the $A^{x / y}$, where $x=i, j$ and $y=Y, \$$, sings of coefficients in equation (3.3). The sign conditions derived for equation (3.3) are relevant below. Coefficients $\left(A^{B / Y}, A^{B / \$}, B^{A / Y}\right.$, and $\left.B^{A / \$}\right)$ on the exchange rates of the neighbor country's currency vis-à-vis the yen and the dollar are unambiguously negative in our model. Coefficients $\left(A^{A / Y}, A^{A / \$}, B^{B / Y}\right.$, and $\left.B^{B / \$}\right)$ on the exchange rates of the home currency vis-à-vis the yen and the dollar are positive under the Marshall-Lerner condition.

(1) The countries $A$ and $B$ import parts from both Japan and U.S. Then, inequalities (3.6) and (3.7) may be or may not be satisfied. Therefore, it does not always hold that $A^{A / Y}>-A^{B / Y}, A^{A / \$}>-A^{B / \$}, B^{B / Y}>-B^{A / Y}$, and $B^{B / \$}>-B^{A / \$}$ in intermediate cases.

(2) The country $i(i=A, B)$ imports parts from Japan only. $\left(\omega_{m}^{U S}=0\right), \alpha_{i 2}=0$. If the production function is symmetric among the neighbor countries - that is, the third term in the left hand side of inequality (3.6) and the right hand side of inequality (3.6) cancel out-then inequality (3.6) is also satisfied. 
Then, $A^{A / \$}>-A^{B / \$}$ for country $A$ and $B^{B / \$}>-B^{A / \$}$ for country $B$.

(3) The country $i(i=A, B)$ imports parts from US only. $\left(\omega_{m}^{J}=0\right), \quad \alpha_{i 1}=0$.

If the production function is symmetric among the neighbor countries-that

is, the third term in the left hand side of inequality (3.7) and the right hand side of inequality (3.7) cancel out-then inequality (3.7) is also satisfied. Then, $A^{A / Y}>-A^{B / Y}$ for country $A$ and $B^{B / Y}>-B^{A / Y}$ for country $B$.

We will analyze interactions of exchange rate policies conducted by the monetary authorities of countries $A$ and $B$ in the following two cases: one is a case where $A^{A / Y}>-A^{B / Y}, A^{A / \$}>-A^{B / \$}, B^{B / Y}>-B^{A / Y}$, and $B^{B / \$}>-B^{A / \$}$ and the other is a case where that $A^{A / Y}<-A^{B / Y}, A^{A / \$}<-A^{B / \$}, B^{B / Y}<-B^{A / Y}$, and $B^{B / \$}<-B^{A / \$}$.

A currency basket is defined as weighted averages of exchange rates of a home currency vis-à-vis the dollar and the yen. Thus, a currency basket peg means that a currency basket of nominal exchange rates is fixed at a level. ' In other words, rates of changes in a currency basket, which is a weighted average of rates-of-changes in the exchange rates, is equal to zero:

$$
\begin{aligned}
& w_{A} \hat{E}^{A / \$}+\left(1-w_{A}\right) \hat{E}^{A / Y}=0 \\
& w_{B} \hat{E}^{B / \$}+\left(1-w_{B}\right) \hat{E}^{B / Y}=0
\end{aligned}
$$

where $w_{i}$ ( for $\left.i=A, B\right)$ : a weight on the dollar in a currency basket for country 
$i$. We suppose a realistic case where $0 \leq w_{i} \leq 1 .^{8}$

When the monetary authorities peg the home currency to a currency basket, relationships between the exchange rates of the home currency vis-à-vis the dollar or the yen and those of the yen vis-à-vis the dollar are shown as follows:

$$
\begin{gathered}
\left\{\begin{array}{l}
\hat{E}^{A / \$}=\left(1-w_{A}\right) \hat{E}^{Y / \$} \\
\hat{E}^{A / Y}=-w_{A} \hat{E}^{Y / \$}
\end{array}\right. \\
\left\{\begin{array}{l}
\hat{E}^{B / \$}=\left(1-w_{B}\right) \hat{E}^{Y / \$} \\
\hat{E}^{B / Y}=-w_{B} \hat{E}^{Y / \$}
\end{array}\right.
\end{gathered}
$$

If the monetary authorities adopt a dollar peg system and a weight on the dollar in a currency basket is equal to unity, the exchange rate of the home currency vis-à-vis the dollar is fixed at a level while the exchange rate of the home currency vis-à-vis the yen co-moves with that of the yen vis-à-vis the dollar. The home currency appreciates against the yen when the dollar appreciates against the dollar.

Both of the monetary authorities are assumed to choose weights on the dollar and the yen in a currency basket in order to stabilize the fluctuation of their own trade balances that is caused by changes in the exchange rates. ${ }^{9}$ Our optimality of the exchange rate policy is to stabilize fluctuations in trade balances in terms of the dollar under a currency basket peg system. We assume 
that the monetary authorities minimize the squared rate of change in trade balances in terms of the dollar. That is, the monetary authorities have the following policy objective functions to minimize:

$$
\begin{aligned}
& \hat{T}_{A}{ }^{2}=\left(A^{A / Y} \hat{E}^{A / Y}+A^{A / \$} \hat{E}^{A / \$}+A^{B / Y} \hat{E}^{B / Y}+A^{B / \$} \hat{E}^{B / \$}\right)^{2} \\
& \hat{T}_{B}{ }^{2}=\left(B^{B / Y} \hat{E}^{B / Y}+B^{B / \$} \hat{E}^{B / \$}+B^{A / Y} \hat{E}^{A / Y}+B^{A / \$} \hat{E}^{A / \$}\right)^{2}
\end{aligned}
$$

By substituting equations (4.5) and (4.6) into equations (4.7) and (4.8), respectively, the objective functions are shown in terms of weights on the exchange rates, $w_{A}$ and $w_{B}$.

$$
\begin{aligned}
& \hat{T}_{A}^{2}=\left\{A^{A / \$}+A^{B / \$}-\left(A^{A / Y}+A^{A / \$}\right) w_{A}-\left(A^{B / Y}+A^{B / \$}\right) w_{B}\right\}^{2} \hat{E}^{Y / \$^{2}} \\
& \hat{T}_{B}{ }^{2}=\left\{B^{B / \$}+B^{A / \$}-\left(B^{A / Y}+B^{A / \$}\right) w_{A}-\left(B^{B / Y}+B^{B / \$}\right) w_{B}\right\}^{2} \hat{E}^{Y / \$^{2}}
\end{aligned}
$$

From equations (4.9) and (4.10), we can derive first order conditions for minimizing their objective functions to obtain the following linear reaction functions: ${ }^{10}$

$$
\begin{aligned}
& \left(A^{A / Y}+A^{A / \$}\right) w_{A}+\left(A^{B / Y}+A^{B / \$}\right) w_{B}=A^{A / \$}+A^{B / \$} \\
& \left(B^{B / Y}+B^{B / \$}\right) w_{B}+\left(B^{A / Y}+B^{A / \$}\right) w_{A}=B^{B / \$}+B^{A / \$}
\end{aligned}
$$

Equation (4.11) is a policy reaction function for the monetary authorities of country $A$, which means that the monetary authorities of country $A$ choose an optimal weight for minimizing their objective function given a weight $w_{B}$ 
chosen by the monetary authorities of country B. Also, equation (4.12) is a policy reaction function for the monetary authorities of country $B$. They choose an optimal weight for minimizing their policy objective function given a weight $w_{A}$ chosen by the monetary authorities of country $A$. Thus, both of the monetary authorities have to determine their optimal weights in a currency basket while they are affected by behavior of the other monetary authorities.

There is a unique equilibrium pair of optimal weights for countries $A$ and $B$ because both of the policy reaction functions are linear functions. From equations (4.11) and (4.12), we derive a pair of optimal weights on the dollar in a currency basket to stabilize their trade balances for both of the countries $A$ and $B$ at the same time:

$$
\begin{aligned}
& w_{A}^{*}=\frac{\left(A^{A / \$}+A^{B / \$}\right)\left(B^{B / Y}+B^{B / \$}\right)-\left(A^{B / Y}+A^{B / \$}\right)\left(B^{B / \$}+B^{A / \$}\right)}{\left(A^{A / Y}+A^{A / \$}\right)\left(B^{B / Y}+B^{B / \$}\right)-\left(A^{B / Y}+A^{B / \$}\right)\left(B^{A / Y}+B^{A / \$}\right)} \\
& w_{B}^{*}=\frac{\left(A^{A / Y}+A^{A / \$}\right)\left(B^{B / \$}-B^{A / \$}\right)+\left(A^{A / \$}-A^{B / \$}\right)\left(B^{A / Y}+B^{A / \$}\right)}{\left(A^{A / Y}+A^{A / \$}\right)\left(B^{B / Y}+B^{B / \$}\right)-\left(A^{B / Y}+A^{B / \$}\right)\left(B^{A / Y}+B^{A / \$}\right)}
\end{aligned}
$$

From equations (4.13) and (4.14), we can obtain a result that the optimal weights $w_{A}^{*}$ and $w_{B}^{*}$ are always between 0 and $1\left(0 \leq w_{A}^{*} \leq 1,0 \leq w_{B}^{*} \leq 1\right)$ in both the case where $A^{A / Y}>-A^{B / Y}, A^{A / \$}>-A^{B / \$}, B^{B / Y}>-B^{A / Y}$, and $B^{B / \$}>-B^{A / \$}$ and the case where $A^{A / Y}<-A^{B / Y}, A^{A / \$}<-A^{B / \$}, B^{B / Y}<-B^{A / Y}$, and $B^{B / \$}<-B^{A / \$}$.

If both of the monetary authorities of countries $A$ and $B$ could, at the same 
time, set $w_{A}^{*}$ and $w_{B}^{*}$, respectively, trade balances would be stabilized in both of the countries. However, it is not always guaranteed that the optimal weights for the both countries are a stable equilibrium.

The condition for a stable equilibrium is

$$
-\frac{A^{A / Y}+A^{A / \$}}{A^{B / Y}+A^{B / \$}}>-\frac{B^{A / Y}+B^{A / \$}}{B^{B / Y}+B^{B / \$}}
$$

This condition is satisfied in the case where $A^{A / Y}>-A^{B / Y}, A^{A / \$}>-A^{B / \$}, B^{B / Y}$ $>-B^{A / Y}$, and $B^{B / \$}>-B^{A / \$}$.

In this case, a pair of the weights proceeds along a converging process toward an equilibrium point implied by the optimal weights $\left(w_{A}^{*}, w_{B}^{*}\right)$. The weights for both of the countries should converge to their optimal equilibrium ones.

Figure 1 shows a case where inequality (4.15) is satisfied. An equilibrium point with the optimal weights $\left(w_{A}^{*}, w_{B}^{*}\right)$ is a stable one on a plain where policy reaction functions of countries $A$ and $B$ are depicted as lines $A A$ and $B B$, respectively. In this case, each of the monetary authorities of countries $A$ and $B$ gradually changes its own weight on the dollar in a currency basket in order to stabilize its own trade balances, given the weight chosen by the other monetary authorities. As the result, the weights for both the countries can eventually reach to an equilibrium point with the optimal weights $\left(w_{A}^{*}, w_{B}^{*}\right)$. 
On the other hand, if

$$
-\frac{A^{A / Y}+A^{A / \$}}{A^{B / Y}+A^{B / \$}}<-\frac{B^{A / Y}+B^{A / \$}}{B^{B / Y}+B^{B / \$}},
$$

a pair of the optimal weights $\left(w_{A}^{*}, w_{B}^{*}\right)$ is an unstable equilibrium. This condition is satisfied in the case where $A^{A / Y}<-A^{B / Y}, A^{A / \$}<-A^{B / \$}, B^{B / Y}<-B^{A / Y}$, and $B^{B / \$}<-B^{A / \$}$. In this case, weights diverge out of the optimal weights once they are off the equilibrium point $\left(w_{A}^{*}, w_{B}^{*}\right)$.

Figure 2 illustrates policy reaction functions of both the countries in a case where inequality (4.16) is satisfied. In this case, an equilibrium point with the optimal weights $\left(w_{A}^{*}, w_{B}^{*}\right)$ is unstable. Suppose that each of the monetary authorities of countries $A$ and $B$ chooses its own weight in order to stabilize its own trade balances, given the weights chosen by the other monetary authorities. The weights chosen by the monetary authorities should diverge out of the optimal weights $\left(w_{A}^{*}, w_{B}^{*}\right)$. Thus, the weights on the US dollar increase and reach to a unity for both the countries, provided that the weight is realistically constrained between 0 and 1 . Both of the monetary authorities eventually adopt a full dollar peg system rather than the optimal currency basket peg system although they have been choosing their weights in order to stabilize their own trade balances. 
Thus, if inequality (4.16) is satisfied, an optimal weight point is unstable. Then, it is difficult for the monetary authorities to change their exchange rate policy to an optimal exchange rate policy.

(2) Coordination failure in optimal currency baskets

Next, we analyze whether the monetary authorities of countries $A$ and $B$ can directly shift their exchange rate system from the current de facto dollar peg system to an optimal currency basket peg system. The shift to optimal currency basket peg system depends on whether each of the monetary authorities can decrease fluctuations in trade balances under the optimal currency basket peg system in comparison with those under the dollar peg system. Especially, each of the monetary authorities should care about fluctuations in trade balances in a case where it shifts to the optimal currency basket peg system while the other monetary authorities keep the dollar peg system.

If both of the monetary authorities adopt the dollar peg $\left(w_{A}=w_{B}=1\right)$ at the same time, fluctuations in trade balances are calculated as follows:

$$
\begin{aligned}
& \hat{T}_{A}{ }^{2}{ }^{\left(w_{A}=w_{B}=1\right)}=\left(A^{A / Y}+A^{B / Y}\right)^{2} \hat{E}^{Y / \$^{2}} \\
& \hat{T}_{B}{ }^{2}{ }^{\left(w_{A}=w_{B}=1\right)}=\left(B^{B / Y}+B^{B / \$}\right)^{2} \hat{E}^{Y / \$^{2}}
\end{aligned}
$$


Suppose that $A$ and $B$ coefficients in equations (4.1) and (4.2) are equal to the $A^{x / y}$, where $x=i, j$ and $y=Y, \$$, coefficients in equation (3.3). Then, it is clear that the fluctuations in trade balances in the case of the dollar peg are larger than those in the case where both of the monetary authorities adopt the optimal currency basket as shown in equation (4.13) and (4.14) except for a case of $A^{A / Y}=-A^{B / Y}$ and $B^{B / Y}=-B^{A / Y}$ The optimal exchange rate regime corresponds to the dollar peg system if $A^{A / Y}=-A^{B / Y}$ and $B^{B / Y}=-B^{A / Y}$. The conditions of $A^{A / Y}=-A^{B / Y}$ and $B^{B / Y}=-B^{A / Y}$ are expressed as follows:

$$
\begin{gathered}
\tau_{i}^{T J} \varepsilon_{J}^{i} \varphi_{J}^{i}\left(1-\alpha_{i 1}\right)-\tau_{i}^{T U S} \varepsilon_{U S}^{i} \varphi_{U S}^{i} \alpha_{i 1}+\left(\tau_{i}^{T B} \varepsilon_{i} \varphi_{j}+\tau_{i}^{I m j} \varepsilon_{i} \varphi_{i}\right) \alpha_{i 1}=\left(\tau_{i}^{T B} \varepsilon_{j} \varphi_{j}+\tau_{i}^{I m j} \varepsilon_{i} \varphi_{i}\right) \alpha_{j 1}(4.19) \\
\tau_{i}^{T U S} \varepsilon_{U S}^{i} \varphi_{U S}^{i}\left(1-\alpha_{i 2}\right)-\tau_{i}^{T J} \varepsilon_{J}^{i} \varphi_{J}^{i} \alpha_{i 2}+\left(\tau_{i}^{T B} \varepsilon_{j} \varphi_{j}+\tau_{i}^{I m j} \varepsilon_{i} \varphi_{i}\right)\left(1+\alpha_{i 2}\right)=\left(\tau_{i}^{T B} \varepsilon_{j} \varphi_{j}+\tau_{i}^{I m j} \varepsilon_{i} \varphi_{i}\right)\left(1+\alpha_{j 2}\right)
\end{gathered}
$$

If we suppose a symmetric two countries whose parameters are equal with each other, we can rewrite equations (4.19) and (4.20):

$$
\begin{gathered}
\tau_{i}^{T J} \varepsilon_{J}^{i} \varphi_{J}^{i}\left(1-\alpha_{i 1}\right)=\tau_{i}^{T U S} \varepsilon_{U S}^{i} \varphi_{U S}^{i} \alpha_{i 1} \\
\tau_{i}^{T U S} \varepsilon_{U S}^{i} \varphi_{U S}^{i}\left(1-\alpha_{i 2}\right)=\tau_{i}^{T J} \varepsilon_{J}^{i} \varphi_{J}^{i} \alpha_{i 2}
\end{gathered}
$$

Thus, the monetary authorities of the two countries should adopt the optimal currency basket peg system rather than the dollar peg system unless equations (4.21) and (4.22) are satisfied in a symmetric two country model. 
Next, we consider a possibility that the monetary authorities adopt the dollar peg system in a situation where equations (4.21) and (4.22) are not satisfied in a symmetric two country model. One possible reason is that the monetary authorities of one county cannot adopt an optimal exchange rate policy because their loss increases if the monetary authorities of the country alone adopt the basket while the other country keeps pegging its home currency to the dollar.

We consider how the monetary authorities of one country should behave, given that the monetary authorities of the other country adopt the dollar peg. For example, suppose that the monetary authorities of country $A$ adopt the above optimal currency basket peg $\left(w_{A}=w_{A}^{*}\right)$ while the monetary authorities of country $B$ adopt the dollar peg $\left(w_{B}=1\right)$. Fluctuations in trade balances for country $A$ are obtained in this case as follows:

$$
\hat{T}_{A}^{2}\left(w_{A}=w_{A}^{*}, w_{B}=1\right)=\left\{\frac{\left(A^{A / Y}+A^{A / \$}\right)\left(B^{B / Y}-B^{A / \$}\right)+\left(A^{A / \$}-A^{B / Y}\right)\left(B^{A / Y}+B^{A / \$}\right)}{\left(A^{A / Y}+A^{A / \$}\right)\left(B^{B / Y}+B^{B / \$}\right)-\left(A^{B / Y}+A^{B / \$}\right)\left(B^{A / Y}+B^{A / \$}\right)}\left(A^{B / Y}+A^{B / \$}\right)\right\}^{2} \hat{E}^{Y / \$^{2}}
$$

When the monetary authorities of country $A$ have options to adopt the dollar peg $\left(w_{A}=1\right)$ or the optimal currency basket peg $\left(w_{A}=w_{A}^{*}\right)$, given that the 
monetary authorities of country $B$ adopt the dollar peg $\left(w_{B}=1\right)$, the monetary authorities of country A compare fluctuations in trade balances between the two options. The monetary authorities of country A compare equation (4.23) with equation (4.17). They prefer the dollar peg to the optimal currency basket peg because fluctuations in trade balance in the case of adopting the dollar peg (equation (4.17)) are less than those in the case of adopting the optimal currency basket peg (equation (4.23)) $\left(\hat{T}_{A}^{2}\left(w_{A}=w_{A}^{*}, w_{B}=1\right)>\hat{T}_{A}^{2}\left(w_{A}=1, w_{B}=1\right)\right)$.

If the monetary authorities of country $A$ chose the optimal currency basket peg $\left(w_{A}=w_{A}^{*}\right)$ while the monetary authorities of country $B$ adopt the dollar peg $\left(w_{B}=1\right)$, country $B$ would have fluctuations in trade balances:

$$
\hat{T}_{B}^{2}\left(w_{A}=w_{A}^{*}, w_{B}=1\right)=\left\{\frac{\left(A^{A / Y}+A^{A / \$}\right)\left(B^{B / Y}-B^{A / \$}\right)+\left(A^{A / \$}-A^{B / Y}\right)\left(B^{A / Y}+B^{A / \$}\right)}{\left(A^{A / Y}+A^{A / \$}\right)\left(B^{B / Y}+B^{B / \$}\right)-\left(A^{B / Y}+A^{B / \$}\right)\left(B^{A / Y}+B^{A / \$}\right)}\left(B^{B / Y}+B^{B / \$}\right)\right\}^{2} \hat{E}^{Y / \$^{2}}
$$

The fluctuations in trade balances in this case are larger than those in the case where both of the countries adopt the dollar peg system $\left(\hat{T}_{B}^{2}\left(w_{A}=w_{A}^{*}, w_{B}=1\right)>\hat{T}_{B}^{2}\left(w_{A}=1, w_{B}=1\right)\right)$. We can explain how each of the monetary authorities adopts exchange rate policy in Figure 3. Point D represents a situation where both of the monetary 
authorities adopt the dollar peg system. Point F represents a situation where the monetary authorities of country A adopt an optimal currency basket peg system while the monetary authorities of country $B$ adopt keep the dollar peg system. If fluctuations in trade balances at point $F$ are larger than those at point $D$, the monetary authorities of country A should not change its own weight on the dollar from $w_{A}=1$ to $w_{A}=w_{A}^{*}$. Thus, both of the monetary authorities should keep pegging their home currencies to the dollar if their trade balances fluctuate more widely in the case of the optimal currency basket peg than in the case of the dollar peg. At this time, they face in a coordination failure that they are forced to adopt the dollar peg even though the optimal currency basket peg is to minimize the fluctuations in trade balances if they adopt the optimal currency basket peg at the same time. Only if both of the monetary authorities coordinated to adopt the optimal currency basket peg at the same time, they peg their home currencies to the optimal currency basket.

\section{Conclusion}

We examined the question of choosing the exchange rate regime for emerging 
market economies that export goods to the United States, Japan, and neighbor countries. The optimal exchange rate regime is defined as the one that minimizes the fluctuation of the trade balance, as the yen-dollar exchange rate fluctuates. One might object to this framework, since the Asian currency crises were largely caused by capital movements, and not by the trade account problem. There are two reasons why the trade account stabilization is important. First, one of the important triggers that caused sudden reversal of capital (or an attack by speculators) in Thailand was the large current account deficit (about 8 percent of GDP in 1996), partly caused by the overvalued baht. The trade balance is important since it affects the confidence of the exchange rate regime. Second, when capital movements are large, that would drive the currency overvalued and/or the current account into deficits. In order to judge whether the exchange rate is misaligned or not, one needs the "benchmark. " The exchange rate that is calculated to stabilize the real exchange rate gives such a benchmark. Therefore, having calculated such a basket value, it gives a good reference to answer a question whether capital flows are too much or too little to cause misalignment.

We can draw some policy implications from these conclusions. First, if the 
Asian region that relies on exports to Japan, the U.S., and other regions, wants to avoid a boom and bust cycle due to under- and over-valued exchange rates, the real effective exchange rate must be managed. In particular, the basket currency regime is helpful. Second, the choice of the exchange rate regime (or weights in the basket) may depend on your neighboring country's choice of the regime. There may be coordination failure. Given the dollar peg of the neighboring country, the choice is the dollar peg, and the neighboring country decides the choice in the same manner. However, both countries would be better off to move to a basket currency regime with more weights on the yen, if the decisions are made simultaneously. Third, in order to help the calculation of such a basket tailored to each country, it may be helpful to calculate and publish the typical currency basket unit for the region. Such a currency unit (say, Asian Currency Unit, or ACU) has weights on the U.S. dollar, the yen, and the euro. Each Asian country manages its own currency within the reasonable band around the ACU, then the coordination failure may be avoided. Calculation of such a currency unit and simulations of the trade balances under the basket system is left for future work.

Although this paper simplifies many aspects of the real world, the essential 
points, we believe, are very relevant to the real world. Asian countries will benefit from coordination with each other in choosing the exchange rate regime. 
Bénassy-Quéré, Agnès (1999) "Optimal Pegs for East Asian Currencies, " Journal of the Japanese and International Economies, vol. 13, 44-60.

Bhandari, Jagdeep S. (1985) "Experiments with the optimal currency composite," Southern Economic Journal, vol. 51, no. 3 (January): 711-730. Eichengreen, Barry (1999) Toward a New International Financial Architecture: A Practical Post-Asia Agenda. Washington, D.C., Institute for International Economics.

Flanders, M. June and Asher Tishler (1981) "The role of elasticity optimism in choosing an optimal currency basket with applications to Israel," Journal of International Economics, vol. 11, 395-406.

Flanders, M. June and Elhanan Helpman (1979) "An Optimal Exchange Rate Peg in a World of General Floating," Review of Economic Studies, " The Review of Economic Studies (July): 533-542.

Frankel, Jeffrey and Shang Jin Wei (1994) "Yen bloc or dollar bloc? Exchange rate policies of the east Asian economies," in T. Ito and A. O. Krueger, eds., Macroeconomic Linkage: Savings, Exchange Rates, and Capital Flows, Chicago, 


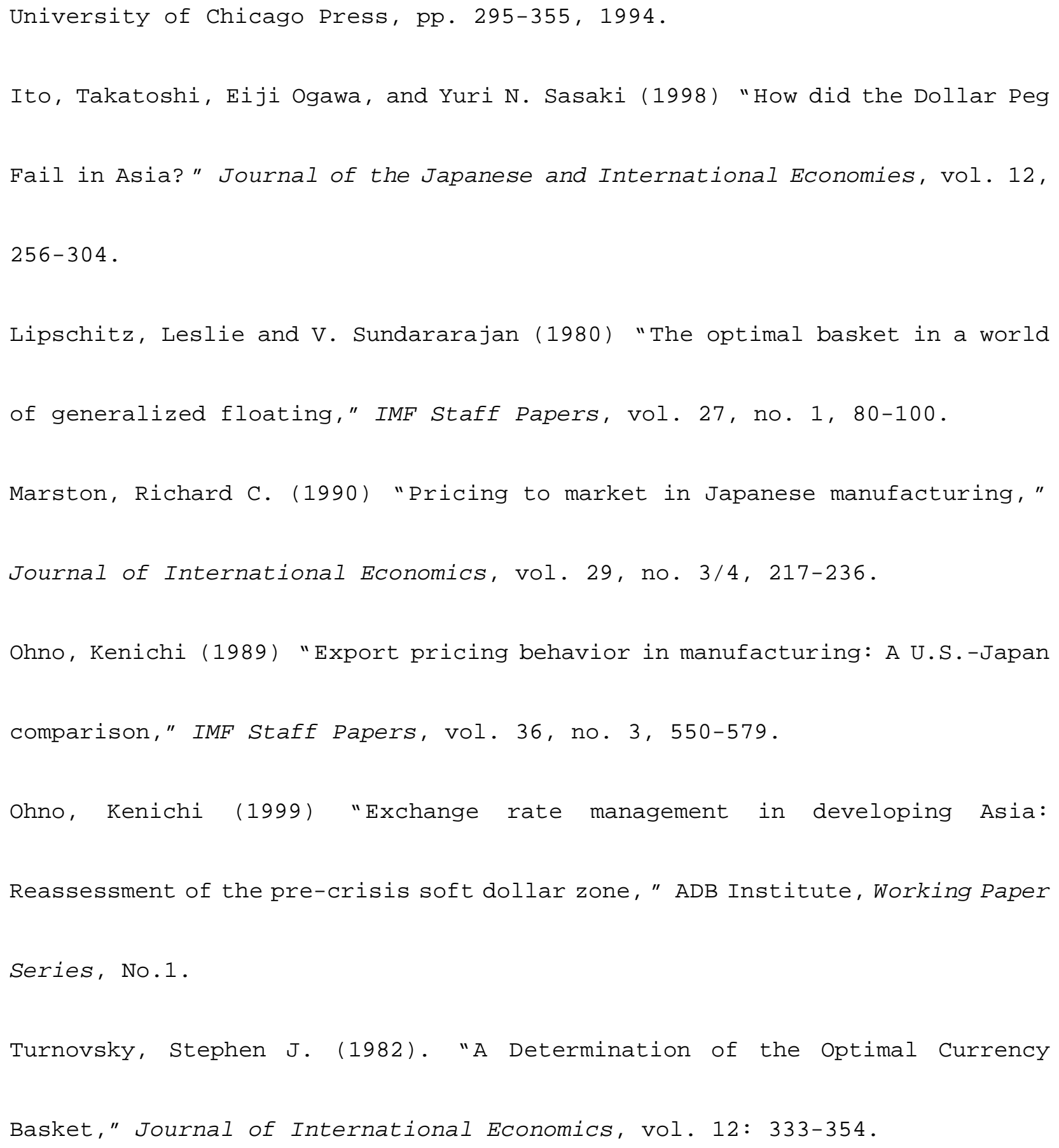




\begin{tabular}{|l|r|r|r|r|}
\hline Table 1: & Export shares by destination \\
\hline $\begin{array}{l}\text { Exports } \\
\text { from }\end{array}$ & $\begin{array}{l}\text { to } \\
\text { Japan }\end{array}$ & to US & $\begin{array}{l}\text { to } \\
\text { NIEs 4+ASEAN4 }\end{array}$ & To EU4 \\
\hline Korea & 19.5 & 19.8 & 10.8 & 9.0 \\
\hline Singapore & 17.6 & 16.9 & 32.0 & 10.5 \\
\hline $\begin{array}{l}\text { Indonesia } \\
\text { Thailand }\end{array}$ & 23.4 & 11.3 & 32.8 & 15.1 \\
\hline Malaysia & 22.7 & 13.8 & 21.5 & 9.6 \\
\hline $\begin{array}{l}\text { Philippine } \\
\text { S }\end{array}$ & 20.5 & 17.5 & 34.1 & 10.4 \\
\hline China & 20.4 & 11.5 & 24.7 & 10.4 \\
\hline
\end{tabular}

Notes:

All data are from 1997, except Indonesia exports to Taiwan, and Philippine exports to Taiwan, 1996.

EU4=Germany, France, UK, Italy

ASEAN4=Indonesia, Thailand, Malaysia, Philippines

NIEs4=Korea, Taiwan, Hong Kong, Singapore

Source: Economic Planning Agency, Asian Economies 1999 . 


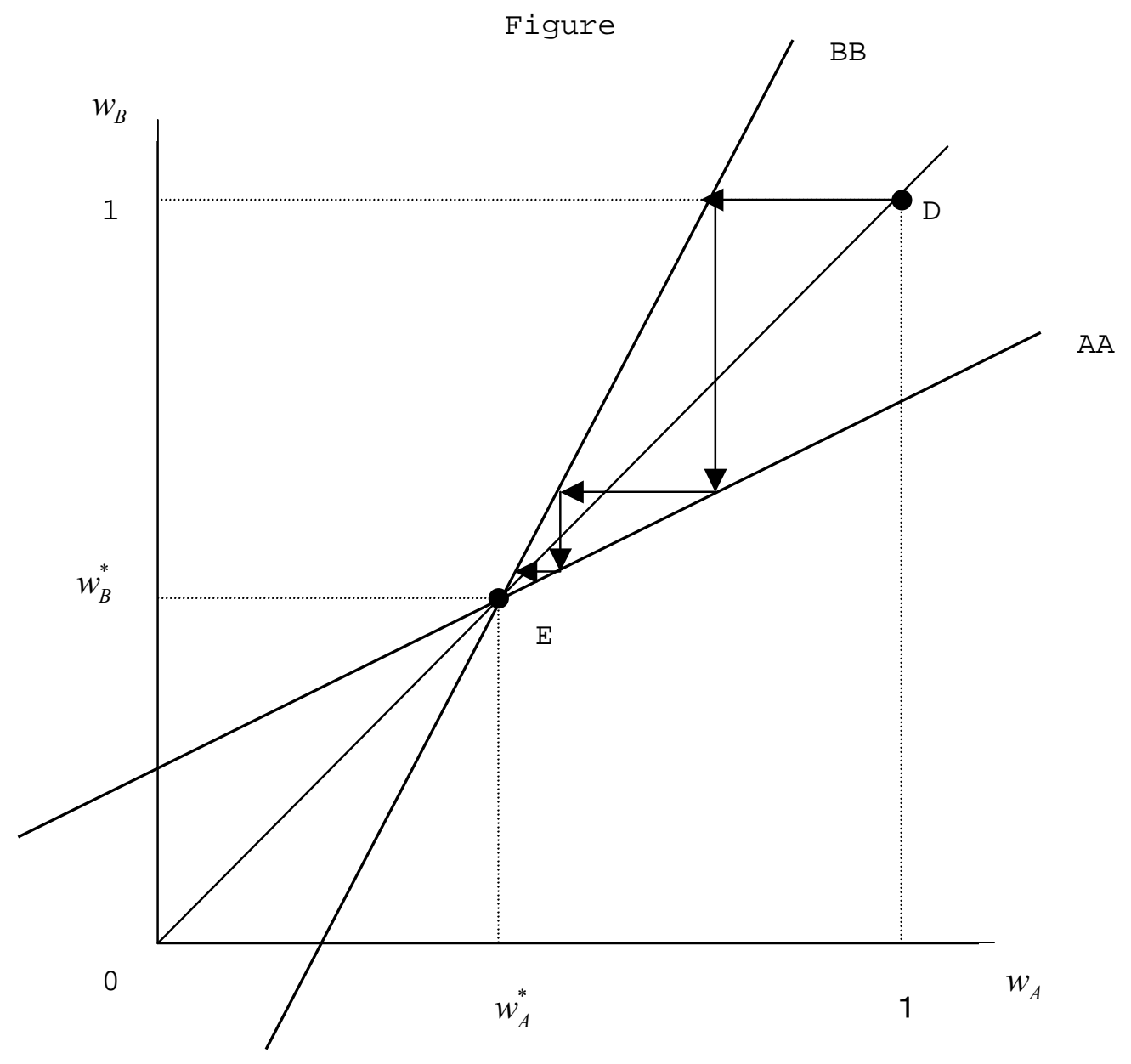




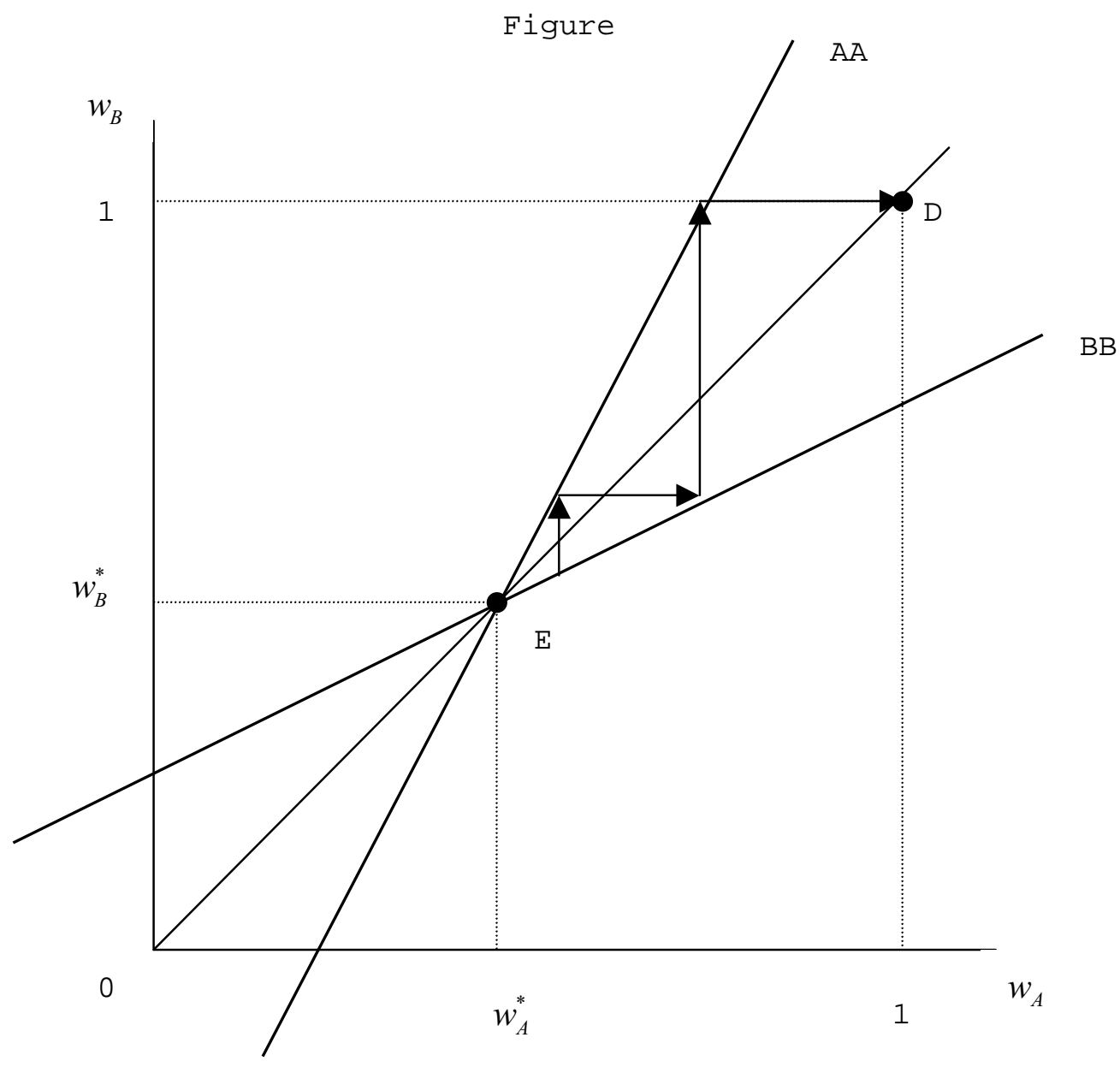




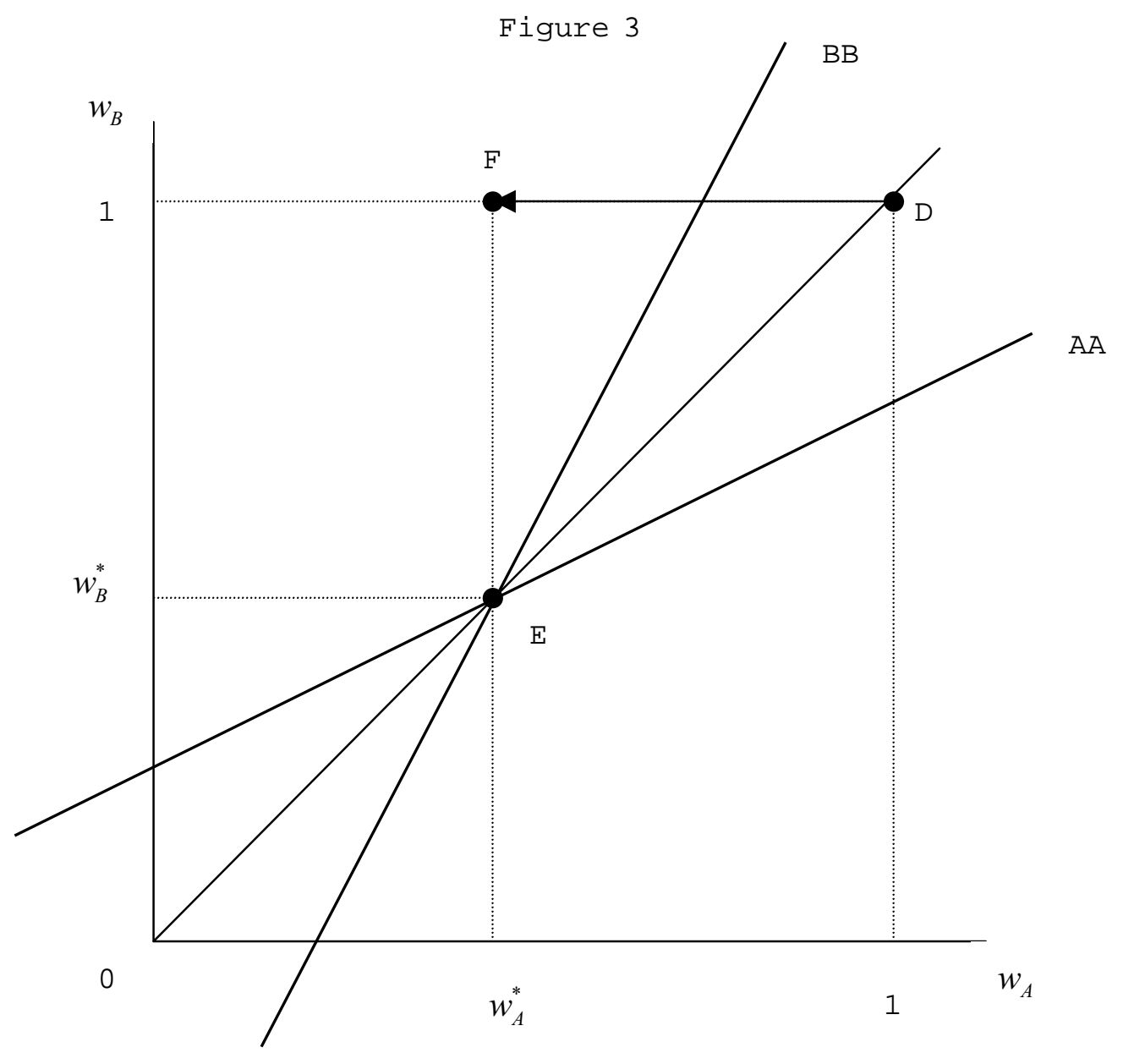


Notes:

1 Several Asian countries including Thailand and Korea before the currency crisis claimed that they were adopting a basket system, or a managed float system. However, the actual movements of the exchange rates suggest that the weight of the dollar was quite high. See Frankel and Wei (1994). In that sense, we call the pre-crisis regime as the de facto dollar peg.

2 The so-called "two-corner solution" has become a popular view among some researchers and policy makers in the post-crisis discussions. (See Eichengreen (1999), for example.) According to this view, free floating, an ultimate flexibility, and a currency board, ultimate inflexibility, are only stable regime in the long run. Any intermediate regime-managed float or fixed exchange rate regime without adopting the currency board-is unstable. Advocates of the two corner solution cite the fact that Hong Kong and Argentina, both currency board economies, survived the currency crisis of the neighboring economies. It is not advisable for countries that export substantial volumes to Japan as well as the United States to adopt the exchange rate regime pegged to the U.S. dollar. Hong Kong seems to be an exception, as it is a small open country with lots of reexports and with high labor and price flexibility of domestic markets. The currency board of the Hong Kong type is not suitable for other Asian economies.

Would the free floating exchange rate a recommended exchange rate regime to other Asian economies? If one believes that the market will (most of the time) determine the exchange rate at the level (almost) consistent with fundamentals, then the free floating is advisable. However, if one believes that the market will (too often) drive the exchange rate to the level (clearly) misaligned with the fundamentals, then policy actions to the domestic market and some direct interventions to the exchange rate market may be called for. The latter view is more convincing in the view of the following evidence. First, even advanced countries find it necessary to intervene occasionally. Foreign exchange rates sometimes become misaligned with fundamentals. The U.S. dollar in 1984-85 and the yen in 1995 are the obvious example of overvaluation. Misalignment needs to be corrected by intervention and some policy adjustment. Second, the worst of the Asian crises, say November 1997 to January 1998, came long after the Asian economies moved to flexible exchange rate regime. When contagious crises feed each other among the regional economies, free floating regimes would cause a downward spiral of the region's currencies. Thus, a devaluation of a currency would bring down the currencies of trade- and investment-related countries. Those who praise China to be a barrier to stop a contagious devaluation spiral in the region by maintaining the fixed exchange rate should also be advocating some sort of managed float in times of crisis.

3 Flanders and Helpman (1979), Lipschitz and Sundararajan (1980), and Flanders and Tishler (1981) emphasized only the real side of the economy in modeling the currency basket peg issue. On the other hand, Turnovsky (1982) and Bhandari (1985) used a general equilibrium macroeconomic model which included capital mobility.

4 Ohno (1989) examined pass-through effects of exchange rates on export pricing behavior in manufacturing after taking account of prices of raw materials. Marston (1990) modeled a similar pricing to market model.

5 In our model, Japanese and US suppliers of parts are not assumed to price to markets because many suppliers exist and they behave competitively. Parts are more difficult to differentiate compared to brand-name products.

6 Bénassy-Quéré (1999) and Ohno (1999) analyzed pegging the US dollar as a 
coordination failure.

7 A currency basket of nominal exchange rates is fixed at a level because we suppose that economies experience no inflation. The monetary authorities should adopt a crawling currency basket system if the economies experience positive rates of inflation that are different from those in the United States and Japan.

${ }^{8}$ We limit a realistic case though it is theoretically possible to suppose $1<w_{i}$.

9 The assumption was made in Ito, Ogawa, Sasaki (1998). Alternatively, we may assume that the monetary authorities minimize absolute variations of the trade account to GDP ratio. Bénassy-Quéré (1999) assumed that the monetary authorities are to stabilize both their external competitiveness and the real price of their external debt.

We can obtain the linear reaction functions because we assume quadratic functions of rate of change in trade balances. It is usual to consider

fluctuations of trade balances as a second order of moment though it is, in general, unnecessary to limit a second order of moment. We can obtain non-linear functions if we assume more general form of objective functions. 